\title{
Lumbar Sympathetic Nerve Trunk
}

National Cancer Institute

\section{Source}

National Cancer Institute. Lumbar Sympathetic Nerve Trunk. NCI Thesaurus. Code C52828.

The inferior portion of the sympathetic trunk comprising four lumbar gang lia, connected by interganglionic cords. 